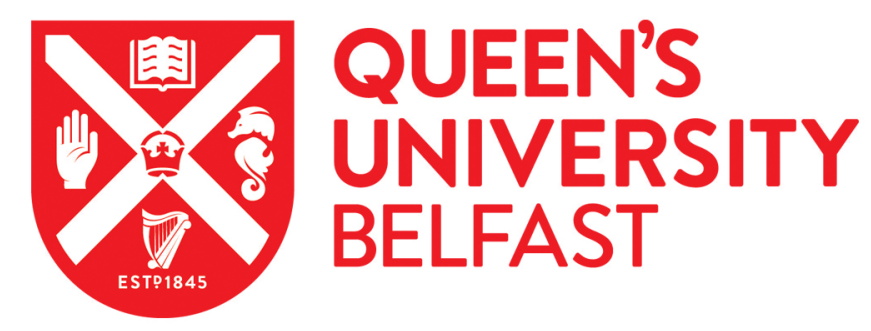

\title{
The governance practices of sharing platforms: Unpacking the interplay between social bonds and economic transactions
}

Zhang, Y., Pinkse, J., \& McMeekin, A. (2020). The governance practices of sharing platforms: Unpacking the interplay between social bonds and economic transactions. Technological Forecasting and Social Change, 158, [120133]. https://doi.org/10.1016/j.techfore.2020.120133

Published in:

Technological Forecasting and Social Change

Document Version:

Publisher's PDF, also known as Version of record

Queen's University Belfast - Research Portal:

Link to publication record in Queen's University Belfast Research Portal

\section{General rights}

Copyright for the publications made accessible via the Queen's University Belfast Research Portal is retained by the author(s) and / or other copyright owners and it is a condition of accessing these publications that users recognise and abide by the legal requirements associated with these rights.

Take down policy

The Research Portal is Queen's institutional repository that provides access to Queen's research output. Every effort has been made to ensure that content in the Research Portal does not infringe any person's rights, or applicable UK laws. If you discover content in the Research Portal that you believe breaches copyright or violates any law, please contact openaccess@qub.ac.uk. 


\title{
The governance practices of sharing platforms: Unpacking the interplay between social bonds and economic transactions
}

\author{
Yaomin Zhang ${ }^{\mathrm{a}}$, Jonatan Pinkse ${ }^{\mathrm{a}, *}$, Andrew McMeekin ${ }^{\mathrm{b}}$ \\ ${ }^{a}$ Manchester Institute of Innovation Research, Alliance Manchester Business School, The University of Manchester, Booth Street West, Manchester M13 9PL, UK \\ ${ }^{\mathrm{b}}$ Sustainable Consumption Institute, The University of Manchester, Booth Street West, Manchester M13 9PL, UK
}

\section{A R T I C L E I N F O}

\section{Keywords:}

Sharing economy

Governance practices

Governance mix

Social bonding

Economic transaction

\begin{abstract}
A B S T R A C T
The sharing economy represents a form of governance that combines practices which facilitate social bonds and economic transactions. Based on the understanding that enabling desired socio-economic relations between individuals forms the core of the governance of sharing activities, this paper develops a conceptual framework which shows how governance practices for sharing vary in terms of the weight given to social bonding development and economic transaction facilitation. Drawing on literature from management, marketing, economics and sociology as well as empirical studies on the sharing economy, this paper identifies the governance practices to which sharing economy organizations resort to different degrees and in different ways to structure their sharing activities. Potential contradictions and complementarities between governance practices are specified as they can be an important source shaping the specific governance mix of sharing economy organizations. The proposed framework contributes to a fine-grained understanding of the complexity of governance in the sharing economy, it highlights the relevance of the interplay between the social and economic governance practices, and it lays the foundation to empirically capture the governance mix of sharing economy organizations.
\end{abstract}

\section{Introduction}

Many organizations are now seen as being part of the sharing economy, even if in their business models are vastly different (Acquier, Daudigeos, \& Pinkse, 2017; Mair \& Reischauer, 2017). In mobility, for example, the ride-hailing platform Uber and the ridesharing platform Skjutsgruppen are both considered sharing platforms, but the former is a profit-oriented multinational corporation making random connections between strangers while the latter is a local environmental movement in Sweden motivating people to become friends and travel in groups for an equal share of the cost. Playing the role of intermediaries, what both organizations have in common is that they have built a business model around the creation of relationships between people on a Web 2.0-based platform and incentivize the exchange of a good or a service (Belk, 2014). Both organizations also face the challenge of looking for ways to encourage users to participate in their platform and to maintain a degree of trust between them so they will continue doing so. A key difference, though, is the type of interpersonal relationship they consider ideal to encourage user participation on their platform and create value. Moreover, they rely on different governance practices 'to encourage participation and to direct, coordinate, and control interactions among individuals' (Reischauer \& Mair, 2018, p. 221). While the governance of relationships between users is a key feature of sharing platforms, the practices that sharing economy organizations have adopted for this purpose vary widely (Perren \& Kozinets, 2018; Reischauer \& Mair, 2018).

Governance is 'the means by which to infuse order' with the aim to mitigate conflict and realize mutual gains (Williamson, 2005, p. 3). For an organization, governance concerns the construction of relational systems which provide structure to activities (Scott, 2013) and involves practices that provide direction and control and manage relationships between various stakeholders (Mair, Mayer, \& Lutz, 2015). Governance is a well-studied topic, but it has unique features in a sharing economy context because value creation depends on the facilitation of interactions between platform users that do not have a formal relation with the sharing economy organization (Reischauer \& Mair, 2018). As the organization is merely an intermediary connecting users, the potential governance problems are immense because users who offer and users who demand goods or services will only continue using the platform if there is sufficient trust that their counterpart will deliver. To structure sharing activities and build trust between users, some sharing economy organizations put a stronger emphasis on building personal

\footnotetext{
* Corresponding author.

E-mail addresses: yaomin.zhang@manchester.ac.uk (Y. Zhang), jonatan.pinkse@manchester.ac.uk (J. Pinkse), andrew.mcmeekin@manchester.ac.uk (A. McMeekin).
} 
connections, fostering communities, and developing social norms of interaction among individual users of a platform (Belk, 2014), while other organizations focus more on contracting, pricing, and maximizing the economic return for the users and the platform (Eckhardt \& Bardhi, 2015). Simply put, sharing economy organizations use specific governance practices to facilitate two types of interpersonal relationships - social bonding and economic transaction - that form the foundation of how users interact on their platform. Although this duality has been conceptualized before, reflected in sharing vs exchange (Belk, 2007; Habibi, Kim, \& Laroche, 2016), non-market vs market (Eckhardt \& Bardhi, 2016; Laurell \& Sandström, 2017), and public vs private (John, 2013), in what way specific governance practices facilitate social bonding and economic transaction, respectively, to direct, coordinate and control individual actions and group activities is less well understood.

The main objective of this paper is to conceptualize how organizational governance practices structure interpersonal relationships between users of sharing platforms and whether these practices are geared more towards developing social bonds or towards generating economic transactions. Based on theoretical insights from management, marketing, economics and sociology as well as the empirical sharing economy literature from across disciplines, we propose a conceptual framework that identifies the practices that sharing economy organizations can resort to, to govern how users interact when sharing goods or services on their platform. Our framework distinguishes between governance practices in terms of their motivational, interactional, and institutional dimension and the relative emphasis put on facilitating social bonds or economic transactions. Our aim is not only to identify specific governance practices but also to analyse the interplay between the practices in a governance mix. We conceptualize potential complementarities and contradictions between practices when used jointly in a governance mix.

With our paper, we seek to make several contibutions to the sharing economy literature. Our framework provides a fine-grained insight into the nature of and the interplay between the governance practices that sharing economy organizations use to facilitate social bonds and economic transactions. In doing so, we move beyond the simple dichotomy of pure sharing and pure exchange (Belk, 2007; Habibi et al., 2016) and show which governance practices form the basis for building the type of interpersonal relationship sharing economy organizations rely on to encourage user participation on their platform. With our framework we lay the foundation to empirically capture the governance practices that sharing economy organizations use. Moreover, we show which practices are more likely to be used jointly in a governance mix because they are complementary, and which seem mutually exclusive because they are in contradiction with each other. We thus provide insight into the stability of specific governance mixes and the extent to which there seems to be alignment between the purpose and the governance of sharing platforms. Gaining a deeper understanding of how sharing activities are governed is important as it shows to what extent sharing economy organizations try to deliver on the promise of 'new forms of collaboration, solidarity and social bonding' or instead just 'recreate the inequalities of the capitalist markets, but in different ways' (Acquier et al., 2017, p. 2; Benkler, 2017; Schor, Fitzmaurice, Carfagna, Attwood-Charles, \& Poteat, 2016). Our framework explains why so many views exist with regard to the promises and paradoxes of organizing the sharing economy (Acquier et al., 2017; Murillo, Buckland, \& Val, 2017).

\section{Setting the boundary of the sharing economy}

The 'sharing economy' as a term became popular after the emergence of the eye-catching cases of Uber and Airbnb around 2013. Its content has vastly expanded since then with the re-inclusion of more traditional sharing activities and the business model innovations of platform organizations which adopt diversified practices of combining the social elements of 'sharing' and the market elements of 'economy.' There is a large diversity in the types of organizations that are associated with the sharing economy and definitions tend to diverge (Acquier et al., 2017). According to Gerwe and Silva (2020), definitional debates revolve around three issues: 1) the boundaries, i.e., which organizations belong to the sharing economy; 2) the tensions between social, community-related elements and economic, marketrelated elements; and 3) what assets are shared, i.e., physical and/or human assets. Ambiguities also exist around whether the shared resources should be underutilized (Botsman, 2013; Muñoz \& Cohen, 2017), whether the assets need to be totally privately owned (Frenken, Meelen, Arets, \& Van de Glind, May 2015), and whether the process could involve the transfer of ownership or commercial activities (Frenken et al., May 2015; Hamari, Sjoklint, \& Ukkonen, 2016). Definitions will continue to evolve as organizations in this space will keep changing their 'sharing' activities. For example, while many platforms started out relying on underutilized assets and facilitating peer-to-peer transactions, some are already moving away from this (Gerwe \& Silva, 2020).

Since we seek to explain the variety of organizational governance practices across platforms we adopt a fairly broad definition of the sharing economy. Following Gerwe and Silva (2020, p. 71), we consider 'the sharing economy broadly as a socioeconomic system that allows peers to grant temporary access to their underutilized physical and human assets through online platforms'. This definition fits our view of the sharing economy as we see it as a confluence of for-profit and nonprofit organizations. It allows us to compare rather different platforms and their governance practices which aim to develop social bonds or generate economic transactions. Moreover, the definition includes platforms that share physical assets, human assets, or both. As we will explain in Section 5, we expect the nature of the assets to be related to the ways in which sharing platforms govern interpersonal relationships between users. While this definition comprises a wide variety of platforms, designing and developing effective strategies, approaches, and technical infrastructures to govern the interpersonal relationship and create value have become an important focus for all of them (BlaBlaCar, 2018; Perren \& Kozinets, 2018; Reischauer \& Mair, 2018).

\section{Governance practices to manage interpersonal relationships in the sharing economy}

In this paper, we adopt an institutional perspective on governance which proposes that an organization's governance practices craft order and bring structure to organizational activities (Williamson, 2005) and provide the stimuli, resources, guidelines, and constraints for individual actions and actors (Scott, 2013). The infusion and maintenance of order and structure involve providing proper incentives, shaping human interaction, and forming shared values, norms and rules for key actors (Scott, 2013). An institutional perspective thus considers the governance of interpersonal relations as having a motivational, interactional, and institutional dimension that work together in bringing order and structure to organizational activities. Order and structure can be delivered and achieved through the use of symbolic systems such as interpretation and framing, the building of social ties and interaction modes of different characteristics, the emergence of activity routines, and the creation of artifacts such as technical tools, all to shape individual perception and bring about repetitive modes of individual action (Giddens, 1997; Scott, 2013). Hence, governance contains elements of social bonding and economic transaction which have long been identified as co-existing modes to manage interpersonal relations in markets and society (Polanyi, 1957; Zelizer, 2012), also beyond a sharing economy context.

Social bonding refers to an individual's social ties which can differ in terms of strength and binding force. The discussion of people's motivation to build social bonds in the community can be traced back to the intuitive 'conscience' and natural will that Tönnies (1887/2001) 
Table 1.

Governance practices to facilitate social bonds and economic transactions.

Interpersonal relationship development

\begin{tabular}{|c|c|c|}
\hline Dimension & Social bonds & Economic transactions \\
\hline Motivational & Shared desire and experience for pleasure, sociality and communal support & Pursuing profitability and efficiency \\
\hline Interactional & Reciprocal interaction and binding sentiment & Immediate and calculative interaction \\
\hline Institutional & Social consensus and norms & Contracts and control mechanisms including sanctions and assurances \\
\hline
\end{tabular}

proposed. This intuitive conscience and natural will comes from the desire for pleasure, as well as the shared experience and memory of pleasure, in contrast to the 'self-consciousness', calculative and rationalchoice-making will, which has widely been identified in economic transactions in the market. With regard to the interaction form in social bonding, Granovetter (1973, p. 1361) defines the 'strength' of a positive and symmetric interpersonal tie as 'a (probably linear) combination of the amount of time, the emotional intensity, the intimacy (mutual confiding), and the reciprocal services which characterise the tie.' So, social bonding, in a positive and symmetric sense, not only implies sufficient interpersonal interaction but also involves reciprocity, emotion, and intimacy. In terms of its institutional foundation, Hirschi (1969) uses 'social bonds' to refer to individuals' binding ties with families, schools, workplaces or communities. The stronger a person's social bonds, the less likely they will conduct deviant behavior (Hirschi, 1969). Social bonds not only denote stronger ties between people but also infuse individuals with the values and norms of the group or society they are in, working as an important mechanism to guide and discipline individual actions. Social consensus and norms produced and reproduced in individual and collective activities provide stability and meaning to the working of social bonding (Tönnies, 1887/ 2001).

An economic transaction is the relationship of trading, exchanging and contracting between two or more parties in the market (Williamson, 1979). Involved parties are motivated to act upon the rational calculation of financial gains and costs (Tönnies, 1887/2001; Weintraub, 2007). In the neoclassical market, pricing is considered as the most important mechanism in the operation of economic transactions (Weintraub, 2007), while New Institutional Economics emphasizes the importance of contract designs and laws instead (Williamson, 1979, 1985). Ex-post institutions such as vertical integration and assurance instruments could be adopted to complement or substitute for contracts to economize on transaction costs (Williamson, 1979, 1985). So, in an economic transaction, with involved parties acting based on calculative rationality of costs and benefits, the exchange happens mainly through price signals, contracting and assurance instruments to safeguard the transactions. Pricing, contracting, and assurance instruments form the institutional basis to structure interpersonal relationships between market participants that exchange goods and services.

In line with this institutional perspective on governance (Scott, 2013) and to identify the governance practices that sharing economy organizations can resort to, we propose three dimensions which constitute the foundation of initiating and sustaining social bonds and economic transactions: a motivational dimension which reflects and promotes the compatible incentives of key actors to interact; an interactional dimension which facilitates the appropriate form of interpersonal interaction; and an institutional dimension which establishes the compatible rules, norms, and alternative control mechanisms that provide stability to the interpersonal relationships. Driven and supported by distinct cognitive, behavioral and institutional bases, developing social bonding and facilitating economic transaction are distinct along the three dimensions (see Table 1). We posit that social bonding development contains a motivational dimension of shared desire and experience for pleasure, sociality, and communal support, an interactional dimension of reciprocal interactions and binding sentiment; and an institutional dimension of social consensus and norms. In contrast, economic transaction facilitation includes a motivational dimension of pursuing profitability and efficiency; an interactional dimension of immediate and calculative interactions; and an institutional dimension of contracts and control mechanisms including sanctions and assurances.

While we present the governance practices that facilitate social bonding and economic transactions as a clear-cut dichotomy, they are ideal types that form the endpoints of a continuum (Doty \& Glick, 1994). In practice, sharing platforms exhibit a more complex mix of governance practices to manage interpersonal relations (Zelizer, 1988, 2012). Moreover, large organizations like Uber and Airbnb are not homogenous units (Lutz \& Newlands, 2018). They tend to offer various different sharing options on the same platform or operate several platforms across sectors such as UberEats and Airbnb Experiences. Given the differences in their specific offerings and market context, these organizations will resort to a different mix of governance practices for each of their sharing options or platforms. For example, in the case of Airbnb, whether users opt for a shared room, private room, or entire home will have implications for their motivation to make use of the service, the expected interaction with other platform users, and the need for control mechanisms. While the shared room option is more likely to rely on social bonding, it also requires stricter practices to handle trust issues as people feel more vulnerable (Lutz \& Newlands, 2018).

In their role as intermediaries, sharing economy organizations exert influence on the ways in which participants engage in sharing platforms. They utilize the underlying symbolic systems, featured interaction modes, activity routines, and technical objects of social as well as economic practices to different degrees (Sundararajan, 2016) and they combine them in different ways (Mair \& Reischauer, 2017). Recent evidence shows that sharing economy organizations strategically design their governance practices and ' $[\mathrm{e}] \mathrm{ach}$ of these practices encompasses activities to encourage participation and to direct, coordinate, and control interactions' (Reischauer \& Mair, 2018, p. 221). Hence, they purposefully use these practices to make sure that specific types of social and economic relationships develop between users.

The co-existence and interplay of social and economic governance practices to direct, coordinate and control interpersonal relationship development in the sharing economy can be observed from how organizations articulate the definitions of the relationship between individual participants in different ways. Many sharing economy organizations assume or define the relationship between users as 'contractual'; the activities they conduct are 'transactions' in the legal sense. In its terms and conditions, AirBnB states, for example:

When Members make or accept a booking, they are entering into a contract directly with each other. Airbnb is not and does not become a party to or other participant in any contractual relationship between Members, nor is Airbnb a real estate broker or insurer. ${ }^{1}$

Nonetheless, Airbnb co-founder Joe Gebbia argued that the promise of building up social relationships forms a key component which they deliberately designed into their platform:

\footnotetext{
${ }^{1}$ Airbnb (2020), Terms of Service for European Users, Retrieved 22 January 2020, from https://www.airbnb.co.uk/terms.
} 
How do we design for just the right amount of (personal information) disclosure (in the interpersonal communication process)? We use the size of the box to suggest the right length, and we guide them with prompts to encourage sharing. We bet our whole company on the hope that, with the right design, people would be willing to overcome the stranger-danger bias. [...] How do sharing and transactions go together? So, let's be clear, it is about commerce. But if you just called it the rental economy, it would be incomplete. The sharing economy is commerce with the promise of human connection. People share part of themselves, and that changes everything. ${ }^{2}$

There are also organizations which describe the relationship between their users as 'communal' and 'social'; community activities and personal interactions form part of the exchange process. For example, Frédéric Mazzella, Founder and CEO of BlaBlaCar, emphasized that their business starts with building community and economic gains only follow from this activity:

I don't feel any kind of special pressure regarding that [the high expectation for a unicorn to create value], because we know that we are still only scratching the surface of what's possible in terms of optimization. We know that along the way we're building a community where people help each other and that's the most important. And then evaluations or the financial pressures are just something which goes with the development of the activity but it's not the core of the business we are building. The core of the business we're building is a community in 22 countries where people are able to share the cost together. ${ }^{3}$

Still, as Love Home Swap-founder Debbie Wosskow explained, even for community-oriented platforms the economic component remains important as well:

So, to 150,000 homes we are not Airbnb and to that extent we won't ever be Airbnb, in that we are all about building a community in a club. It's not just a purely transactional holiday-based website; it's a community of homeowners. [...] There are two sides of the sharing economy: there's the money end of things, so are you making money and saving money. And there's the experience. And all data demonstrates that those two are of equal importance. ${ }^{4}$

Moreover, it is not uncommon for sharing economy organizations to deliver the interpersonal relationship between participants in obscure terms, or demonstrate it as 'contractual' in legal statements while highlighting the 'communal' nature in other public spaces, e.g. in the forum or the blog, thus ascribing to both discourses without treating them as contradictory. For example, HomeExchange hosts "Members only" Facebook groups to let travelers build social relationships with each other. ${ }^{5}$

To explain how different sharing economy organizations design, effectuate, and balance governance practices and leverage them in distinct ways, we unpack the specific governance practices that deliver the respective outcomes of forming social bonds and economic transactions on the motivational, interactional, and institutional dimensions. We develop our framework based on theoretical insights from a multidisciplinary body of literature from management, marketing, economics, and sociology. We theoretically explain how governance practices in terms of their different motivations, interaction forms, underlying values, norms and rules

\footnotetext{
${ }^{2}$ TED (2016), How Airbnb designs for trust, Retrieved 22 January 2020, from https://www.youtube.com/watch?v=16cM-RFid9U.

${ }^{3}$ An interview with Frédéric Mazzella, Founder and CEO of BlaBlaCar (2016), Retrieved 9 April 2020, from https://www.youtube.com/watch?v= huvhJXSmUmw

${ }^{4}$ Thomson Reuters/Cass Business School (2016), Trust in the sharing economy, Retrieved 22 January 2020, from https://www.youtube.com/watch? $\mathrm{v}=$ H9TVSbWUusw.

${ }^{5}$ HomeExchange (2020), The HomeExchange Membership, Retrieved 22 January 2020, from https://www.homeexchange.com/choose-plan.
}

facilitate social bonding and economic transaction. In addition, we present insights from previously published empirical research on the sharing economy to capture the salient approaches that (1) are observed as being adopted by sharing economy organizations to enable and manage interpersonal relationships and (2) are associated with the respective motivational, interactional, and institutional foundations of social bonds and economic transactions. With this analytical approach, we identify six governance practices that exhibit key differences between the two ideal types of social bonding development and economic transaction facilitation (see Table 2).

\section{Contrasting social bonding development and economic transaction facilitation in governance practices of sharing platforms}

\subsection{The motivational dimension}

To incentivize people to engage in sharing activities, sharing economy organizations' governance on the motivational dimension is realized mainly through the use of symbolic systems to shape individuals' perception on the organization and its sharing activities. Specifically, the two governance practices in which social bonding development and economic transaction facilitation differ on the motivational dimension include the demonstration of organizational identity and specific offerings to individual participants.

\subsubsection{Signaling of organizational identity}

Whether a sharing economy organization gives more weight to the formation of social bonds or to facilitating economic transactions first comes to the fore in its identity. An organization's identity describes 'Who are we' 'What businesses are we in', and 'What do we want to be', and conveys the central, enduring, and distinctive components of an organization (Albert \& Whetten, 2004). The identity directs how an organization allocates resources and implements strategies to meet commitments and it guides individual actions within the organization (Whetten, 2016). Usually communicated through its core goals, mission, or business storytelling, the demonstration of organizational identity sends signals to stakeholders outside the organization and shapes its image (Whetten, 2016). The identity is a strategic device, though, that is used to create a favorable image of the organization (Gioia, Schultz, \& Corley, 2000). Organizations could develop an identity that sits well with strategically relevant stakeholders but might not be fully congruent with their deeply held values and objectives. While sharing economy organizations commonly claim both social and economic objectives, an organization's signaling of its central goal and role, i.e. whether they are socially or commercially focused, has a strong bearing on its business model and self-representation (Schor, October 2014; Wruk, Oberg, Klutt, \& Maurer, 2019). It sends a message to the public about what type of user relationship the organization plans to build, how it organizes the exchange process, and how it invests resources and makes revenues in this process (Constantiou, Marton, \& Tuunainen, 2017), which all contribute to people's consistent or inconsistent perception of the organization's claimed values and practices (Whetten, 2016).

Legal status reflects the general difference in sharing economy organizations' identities. The sharing economy encompasses for-profit businesses, social enterprises, and non-profit organizations. Typically, sharing economy organizations which have a more enduring focus on revenue maximization, market share and assets register as for-profit businesses (Schor, October 2014). Uber, for example, portrays itself as a technology start-up that creates a new standard for consumer convenience, brings in disruptive innovation, ${ }^{6}$ and supports self-

\footnotetext{
${ }^{6}$ Uber Technologies, Inc. - A letter from our CEO. (2019). Uber.com. Retrieved 17 December 2019, from https://investor.uber.com/a-letter-from-our-ceo/?
} 
Table 2.

Governance practices of sharing platforms: A conceptual framework.

Interpersonal relationship development

\begin{tabular}{|c|c|c|c|}
\hline Dimension & Practice & Social bonds & Economic transactions \\
\hline \multirow[t]{2}{*}{ Motivational } & $\begin{array}{l}\text { Signaling of organizational } \\
\text { identity }\end{array}$ & $\begin{array}{l}\text { Stronger signaling of socially focused identity reflects } \\
\text { the inclination to highlight social bonding development }\end{array}$ & $\begin{array}{l}\text { Stronger signaling of commercially focused identity reflects } \\
\text { the inclination to highlight economic transaction facilitation }\end{array}$ \\
\hline & $\begin{array}{l}\text { Promoting specific offerings to } \\
\text { individual participants }\end{array}$ & $\begin{array}{l}\text { Stronger promotion of social benefits indicates the } \\
\text { attempt to align individual motive and behavior with } \\
\text { social bonding development }\end{array}$ & $\begin{array}{l}\text { Stronger promotion of economic benefits indicates the } \\
\text { attempt to align individual motive and behavior with } \\
\text { economic transaction facilitation }\end{array}$ \\
\hline \multirow[t]{2}{*}{ Interactional } & $\begin{array}{l}\text { Creating opportunities for } \\
\text { repeated interpersonal } \\
\text { interaction }\end{array}$ & $\begin{array}{l}\text { Creating more opportunities for repeated interaction } \\
\text { refers more to social bonding development }\end{array}$ & $\begin{array}{l}\text { Creating fewer opportunities for repeated interaction refers } \\
\text { more to economic transaction facilitation }\end{array}$ \\
\hline & $\begin{array}{l}\text { Creating opportunities for } \\
\text { unmediated co-presence }\end{array}$ & $\begin{array}{l}\text { Creating more opportunities for unmediated co- } \\
\text { presence shows a stronger focus on social bonding } \\
\text { development }\end{array}$ & $\begin{array}{l}\text { Creating fewer opportunities for unmediated co-presence } \\
\text { shows a stronger focus on economic transaction facilitation }\end{array}$ \\
\hline \multirow[t]{2}{*}{ Institutional } & $\begin{array}{l}\text { Developing central rules and } \\
\text { norms of sharing activities }\end{array}$ & $\begin{array}{l}\text { Stronger development of communal norms and shared } \\
\text { experiences shows the tendency and is a more } \\
\text { compatible way of forming social bonds }\end{array}$ & $\begin{array}{l}\text { Stronger development of contractual arrangements and } \\
\text { sanctions reveals the tendency and is a more compatible way } \\
\text { of driving economic transaction }\end{array}$ \\
\hline & $\begin{array}{l}\text { Providing intensive assurance } \\
\text { instruments }\end{array}$ & $\begin{array}{l}\text { Weaker provision of intensive assurance instruments } \\
\text { aligns better with social bonding development }\end{array}$ & $\begin{array}{l}\text { Stronger provision of intensive assurance instruments aligns } \\
\text { better with economic transaction facilitation }\end{array}$ \\
\hline Governance style & & 'Loose and decentralized' & 'Tight and centralized' \\
\hline
\end{tabular}

employment. ${ }^{7}$ Algorithm development is a key investment for Uber to connect drivers and passengers and achieve higher exchange efficiency and profitability. It achieves its commercial objective by charging service fees from drivers and passengers and by adopting a surge pricing system. Uber's identity as a technology company is strategic, as it allows them to avoid having to comply with all kinds of regulations that apply to transportation companies. ${ }^{8}$ And, while Uber and Airbnb have both been engaged in community-building initiatives among their users, the underlying motive was the furthering of their commercial objectives. For example, both organizations mobilized their users in US cities such as San Francisco and Portland to lobby regulators to prevent any restrictions for the use of their platforms. They did not bring together users for social bonding purposes but for their own political benefit (Pollman \& Barry, 2016).

In contrast, non-profit organizations, and to a lesser extent social enterprises, explicitly target delivering social objectives related to the improvement of human relations and social wellbeing, provide services with little requirement for a fee, invest more in community management, and involve fewer monetary exchanges between participating individuals (Albinsson \& Perera, 2012; McArthur, 2015). These practices send the signal to participants that social value is a focus of the exchange designed by the organization and influence their perception of the organization (Porter \& Donthu, 2008). For instance, the nonprofit Swedish ridesharing platform Skjutsgruppen defines itself as an environmental movement. It encourages donations from users but requires no compulsory fee. Upcoming trips are posted in groups and shared fees are agreed between drivers and riders. Active in-group conversations are strongly promoted to strengthen social bonds between participants based on the shared environmental value as well as improve the sharing experience. ${ }^{9}$

Therefore, we submit that a stronger signaling of a socially focused identity is a primary reflection of its inclination to highlight social

\section{(footnote continued)}

ga $=2.127271181 .1642215352 .1576610802-1824535341.1575665538$

${ }^{7}$ Become a Driver - 3 Things to Know About Driving | Uber. (2019). Uber.com. Retrieved 9 December 2019, from https://www.uber.com/us/en/drive/how-itworks/

${ }^{8}$ A transport service or a tech company? Uber's future is uncertain. Retrieved 8 April 2020, from https://www.smartcompany.com.au/industries/transportlogistics/uber-london-ban/

${ }^{9}$ Skjutsgruppen. (2019). Old.skjutsgruppen.nu. Retrieved 9 December 2019, from http://old.skjutsgruppen.nu/about_us bonding development in its governance of interpersonal relations. It shapes the organization's choices of the basic exchange mode, resource allocation strategy, and revenue-making channel and signals its potential investment in social value to individual participants. In contrast, a stronger signaling of a commercially focused identity reflects an emphasis on economic transaction facilitation.

\subsubsection{Promoting specific offerings to individual participants}

The second governance element within the motivational dimension concerns what kind of offering a sharing economy organization promotes to motivate individual participants to participate in sharing on their platform. The offering conveys what will be the perceived benefit for people participating in the sharing activities that the organization facilitates. While the signaling of organizational identity tends to shape individuals' perception of the general orientation and public image of the sharing economy organization; the specific offerings show what assured benefits people can expect by engaging in the type of sharing relationship the organization develops. By specifying the payback for individuals who take part in sharing and presenting testimonials and experiences of existing participants, sharing economy organizations create direct incentives for people to participate. Compared to identity, promoting specific offerings forms a more concrete and direct stimulation to motivate people to participate in sharing as it conveys the message "What is in it for them?".

People are motivated to participate in building social bonds for the pleasure they bring, the shared experience, as well as the pursuit for mutual support and community cohesion. In contrast, the expectation for financial gains and efficiency maximization incentivizes people to conduct economic transactions (Tönnies, 1887/2001). In social psychology, self-regard and reciprocity are viewed as two core personal traits concerning cooperative actions (Bogaert, Boone, \& Declerck, 2008). Individuals with the former trait tend to maximize their personal payoffs (Fehr \& Gintis, 2007), while those with the latter trait attach great importance to the payoffs for both themselves and others, as well as reciprocal fairness (De Cremer \& Van Lange, 2001) and equity (Bridoux, Coeurderoy, \& Durand, 2011).

By motivating individual participants with the right benefits, sharing economy organizations can increase the possibility of generating the desired type of relationship between participants. Widely evidenced by sharing economy research, economic benefits - typically the functional and utilitarian performance of the shared resources (Sheth, Newman, \& Gross, 1991), such as quality, convenience, price, and monetary payback - serve as a significant motivator for people to 
engage in sharing (Barnes \& Mattsson, 2017; Benkler, 2004; Bucher, Fieseler, \& Lutz, 2016; Hamari et al., 2016; Lamberton \& Rose, 2012). Yet, social benefits are also a prominent incentive in the sharing economy (Benkler, 2017). They have a strong association with people's social and affective demands of human connection, feeling of pleasure and belonging, or emotional support and communication (Sheth et al., 1991), especially where people seek a sense of community (Barnes \& Mattsson, 2017), want to build durable ties (Wiertz \& Ruyter, 2007), or are influenced by moral boundaries and class inequality (Aptekar, 2016). The stronger the members' incentives for social benefits, the more likely they will behave reciprocally and build enduring ties with their sharing counterparts (Roos \& Hahn, 2017). Besides the two most prominent types of benefits, other motivations, such as the pursuit of environmental sustainability or novelty, can be attached or supportive to either economic or social incentives, depending on the interpretation and condition of the specific sharing economy organization. In the discourse of Didi Chuxing, for example, environmental sustainability is linked with functional value, i.e. improving transportation alternatives and efficiency. ${ }^{10}$

Specifically, sharing economy organizations' promotion of specific benefits to stimulate the compatibility of individual incentives could take effect in two ways. On the one hand, by promising participants explicit economic or social benefits, they attract people who applaud the same value and are more likely to form transactional or bonded relations with each other and reinforce the expected behaviors (Bridoux et al., 2011; Porter \& Donthu, 2008). BlaBlaCar's advertising of saving money and making extra money represents the former, while its promotion of building friendships via carpooling shows the latter. ${ }^{11}$ On the other hand, by taking measures to constrain people's profitmaking motives, some organizations intend to filter out those participants driven by strong commercial incentives and create an environment that allows social bonds to develop (Kyprianou, 2018). Shareyourmeal's prohibition of commercial caterers and restaurants reflects this approach. Technical tools with a constraining effect on individuals' commercial incentives and activities - e.g. a virtual currency where the organization decides the exchange rate based on egalitarian notions (Schor \& Fitzmaurice, 2015) - have also been adopted by the sharing platforms Economy of Hours and BookMooch.

Thus, a sharing economy organization's promotion of stronger social benefits to stimulate individual participants - including promises to deliver social benefits and measures to constrain commercial incentives - is an important indication of an organization's attempt to align individual motives and behavior with social bonding development, while the stimulation with stronger economic benefits reflects the organization's tendency to drive economic transaction.

\subsection{The interactional dimension}

The facilitation of the appropriate interaction mode between individual participants is effectuated by promoting and routinizing compatible interactive behaviors and activities among people. The design of technical infrastructures such as platform features, mediated communication tools, and the delivery of symbolic meanings also play significant parts in advancing this procedure. The two governance practices in which social bonding development and economic transaction facilitation differ on the interactional dimension refer to how the frequency and the media of interpersonal interaction are managed.

\subsubsection{Creating opportunities for repeated interpersonal interaction}

The third governance practice captures to what extent a sharing

\footnotetext{
${ }^{10}$ Social Responsibility - Didi Chuxing. (2019). Didiglobal.com. Retrieved 7 December 2019, from https://www.didiglobal.com/about-didi/responsibility

${ }^{11}$ About Us - BlaBlaCar. (2018). Blablacar.com. Retrieved 16 March 2018, from https://blog.blablacar.com/about-us
}

economy organization creates a context that facilitates repeated interaction between participating individuals, regardless of whether the interaction is mediated or unmediated. The amount of time people spend interacting, which is widely operationalized as the frequency of meeting, is a major contributing factor to the strength of an interpersonal tie (Granovetter, 1973; Krackhardt, 1992). Repeated interaction can also contribute to market transactions, not only by delivering more reliable and qualitative information about pricing (Powell, 1990), but also by generating trust between people (Kramer, 1999; Zucker, 1986), discouraging malfeasance, and developing long-term cooperation (Granovetter, 1985). With the advancement of information and communication technology, mediated communication via telephone, email, social media and other devices is widely adopted in interpersonal interaction. These technologies, which are usually integrated into sharing economy platforms, make frequent, remote communication feasible and help overcome spatial obstacles of interaction (Licoppe, 2004).

Creating opportunities for repeated interaction between individuals, either mediated or face-to-face, is a strong focus of many platform organizations to enable social bonding, including the sharing economy (Kraut \& Resnick, 2012; Porter \& Donthu, 2008; Reischauer \& Mair, 2018). A common approach is promoting meet-ups and events next to the focal exchanges, organized either by the organization or the users themselves (Reischauer \& Mair, 2018). For example, Couchsurfers who share spare living spaces with each other can also join regular meet-ups and events organized by other Couchsurfers in their local communities. ${ }^{12}$ Although freelancers on Fiverr.com offer digital services, the platform is active in arranging offline resources, education, and networking events for members located in different cities around the world. ${ }^{13}$ However, as the failure of Homejoy - a platform for cleaning services - shows, there is a risk of allowing offline interactions between users because once social relationships have developed, they no longer need the platform to connect. ${ }^{14}$ In a mediated manner, developing platform communication tools like messages and features such as 'Follow', 'Friend' and 'Group' is another way to promote repeated interaction (Reischauer \& Mair, 2018). On Didi Hitchhike and Dida Carpool, drivers and riders can keep in touch and carpool repeatedly with the mobile application feature 'Follow' and 'My Friends.' In the book-swapping network BookMooch, members can add each other as 'Friends' and know what their friends, or friends of friends, are collecting and reading. ${ }^{15}$

Not only is repeated interaction essential to building stronger social ties, its symbolic meaning is in highlighting tie strength and bringing in more contacts. Representing individual trustworthiness and reputation, frequency of interaction works as an indicator of relationship strength on many sharing platforms. A case in point is the pet-sitting platform Rover.com, which displays the number of repeat clients on the sitter profile to show the reliability of the pet sitter, ${ }^{16}$ while on Couchsurfing the number of 'friends' reveals that a Couchsurfer is welcoming and trustworthy to connect with. ${ }^{17}$ However, when a platform plays a dominant role in the resource-searching-and-matching process, the chance of interacting and building connections between participants is

\footnotetext{
${ }^{12}$ Couchsurfing. (2019). Couchsurfing.com. Retrieved 9 December 2019, from https://www.couchsurfing.com/events

${ }^{13}$ Fiverr Events. (2020). Fiverr.com. Retrieved 15 January 2020, from https:// www.eventbrite.com/o/fiverr-4664044361

${ }^{14}$ The limits of Uberization: How far can platforms go? (2016) Retrieved 23 January 2020, from https://www.oii.ox.ac.uk/blog/the-limits-of-uberizationhow-far-can-platforms-go/.

${ }^{15}$ Interview with BookMooch founder John Buckman. (2019). Bookmooch.com. Retrieved 9 December 2019, from http://bookmooch.com/about/interview

${ }^{16}$ Information is based on the sitter profiles on the Rover.com website on 9 December 2019.

${ }^{17}$ Information is based on the user profiles on the Couchsurfing website on 9 December 2019.
} 
minor (Bardhi \& Eckhardt, 2012; Kyprianou, 2018). In ride-hailing services such as UberX and UberPool of Uber or Didi Express of Didi Chuxing, where drivers and passengers are randomly matched by algorithms, interpersonal interaction is usually one-off and the chance for social bonding is limited. But for those carpooling models where the passenger searches and negotiates with the driver, e.g. Skjutsgruppen or Didi Hitchhiking of Didi Chuxing, the chance of repeated interaction is relatively higher.

How strongly repeated interpersonal interaction is stimulated differentiates the governance of sharing activities between organizations. We posit that a sharing economy organization which creates more opportunities for repeated interpersonal interaction can be seen as aiming for stronger social bonding development, whereas an organization creating fewer opportunities for repeated interpersonal interaction depends more on facilitating economic transaction to govern sharing activities.

\subsubsection{Creating opportunities for unmediated co-presence}

The fourth practice on which sharing economy organizations' governance varies concerns the degree of creating opportunities for unmediated co-presence between participants, which refers to face-to-face interaction between individuals (Goffman, 2005). The popularity of various forms of mediated communication, e.g. telephone, email, messaging system, video call, social media, adds to the frequency of distant interpersonal interaction. Research shows, however, that faceto-face interaction still plays a vital role for high-quality relationships. Mediated communication tends to complement rather than substitute face-to-face interaction in terms of building social relations (Altman \& Tushman, 2017). Mutual attentiveness and social involvement are more spontaneously formed in face-to-face interaction. Multiple carriers verbal or nonverbal - are available in physical co-presence to deliver intricate information (Giddens, 1997; Goffman, 1990). Visual and nonverbal behavior, such as facial expressions, body movements and postures, eye contacts and gestures, are social cues that affect how an individual perceives, interprets and evaluates others, which in turn relates to whether they want to continue the interaction (Bente, Rüggenberg, Krämer, \& Eschenburg, 2008). Technologies delivering visual and nonverbal content are beneficial for social tasks for which feelings, emotions and social attitudes are important. A lack of visual content tends to deliver less interpersonal information and to make the interaction impersonal (Whittaker, 2003). Although face-toface interaction is not a determinant of social bonding, it orchestrates this process with fewer restraints than mediated communication tools that are less interactive and more impersonal.

In the sharing economy context, face-to-face interaction, verbalized into 'meeting', 'chatting, 'sharing moments', 'welcoming guests', and other discourses, is highlighted to varying degrees. It is not only strongly encouraged but also normed in certain ways by many sharing economy organizations, e.g. offline meet-ups, events, and meeting conventions (Albinsson \& Perera, 2012; Reischauer \& Mair, 2018). For example, diversified face-to-face occasions and interactions between the guests, as well as between the guests and the chef, is what distinguishes Eatwith from traditional dining experiences. ${ }^{18}$ By contrast, there are platforms which base their sharing activities completely on online interaction and platform mediation (Bardhi \& Eckhardt, 2012). Some platforms tend to overlook face-to-face interaction or even explicitly oppose it. On the Indian ridesharing platform Ola, riders and drivers are expected not to share personal information but 'maintain decorum and refrain from indulging in heated discussions or debate(s) with each other' and 'avoid getting personal or overtly friendly with

\footnotetext{
${ }^{18}$ Food Experiences With Locals Around The World | Eatwith. (2019). Eatwith.com. Retrieved 9 December 2019, from https://www.eatwith.com/ pages/how-it-works
}

each other. ${ }^{, 19}$ Considering this negative attitude towards face-to-face interaction, social bonds are unlikely to develop.

Taking the current stage of the sharing economy into account, noninteractive and asynchronous communication technologies such as email, text and non-instant messaging systems are the major forms of mediated communication between distant providers and demanders; yet, face-to-face interaction still plays a significant role in spontaneously forming shared experiences and social bonds between individuals (Hughes, n.d.). Empirical evidence suggesting that positive facial expression and perceived trustworthiness of hosts' photos on Airbnb affects guests' decision-making supports the significance of the quasi-presence of the 'face' in establishing visual-based trust in the sharing economy (Ert et al., 2016; Fagerstrøm et al., 2017). Some sharing economy organizations strongly promote face-to-face interaction between participants, whereas others value flexibility and privacy over sociality, playing down or even opposing face-to-face interaction. Hence, we argue that sharing economy organizations which enable unmediated co-presence and more opportunities for non-verbal communication more strongly focus on developing social bonding, while those mainly using mediated co-presence rely more on facilitating economic transactions.

\subsection{The institutional dimension}

The institutional dimension concerns the rules, norms, and control mechanisms that sharing economy organizations build up to provide stability to individual actions. The formulation and enforcement of systematic rules and norms establish the regulative and normative structures of sharing activities (Scott, 2013), while sophisticated assurance instruments supported by platform technology are a major control mechanism in the sharing economy. On this dimension, we identify two governance practices that reflect the difference between social bonding development and economic transaction facilitation, including what type of constraining rules an organization establishes, and whether it relies on assurance instruments to enforce the established rules and control the sharing process.

\subsubsection{Developing central rules and norms of sharing activities}

The fifth governance practice concerns to what extent sharing economy organizations rely on the underlying rules and norms of either social bonding or economic transaction. The central institutions - that is, the established normative and regulative structures that are used to guide and control the behavior of actors (Scott, 2013) - tend to differ in bonded and transactional relations. Mutual understanding or consensus is reached by people when forming social bonds in the community (Tönnies, 1887/2001). Informal constraints based on the social agreement, such as reciprocal norms, social values, moral obligations and sense of community, are institutionally essential to enable and sustain interactions in social bonding, while formal constraints, including contracts, laws, and sanctions, are more typical institutional structures established to regulate transactions (Nooteboom, 2002; Powell, 1990; Scott, 2013). North (1992, p. 46) describes the difference between informal and formal constraints as 'a continuum from taboos, customs, and traditions at one end to written constitutions at the other.' Informal constraints tend to be oral, implicit and strengthened by social pressure, while formal constraints are more likely in written form, explicit and enforced by recognized authorities. Both types of constraint co-exist and complement each other to facilitate cooperation and stability (North, 1992).

The regulative function of formal rules, binding contracts and sanctions could contradict or even crowd-out the incentive of

\footnotetext{
${ }^{19}$ Olacabs | Terms of Service. (2019). Olacabs.com. Retrieved 9 December 2019, from https://olawebcdn.com/v1/docs/website-tnc.html? source= post page-
} 
developing social bonding (Granovetter, 1985). Introducing legal contracts, sanctions, and surveillance can signal a lack of friendship (Macaulay, 1963), affect participants' perceptions on whether they are making a business or an ethical decision (Tenbrunsel \& Messick, 1999), generate vigilance and impair the positive outcomes of trust (Lumineau, 2014). While responding to reliability concerns, legalistic mechanisms tend to neglect value-related concerns (Sitkin \& Roth, 1993). When binding contracts are applied to regulate cooperation, the involved parties tend to attribute the cooperation of the counterparts to the contractual constraints rather than to the counterparts themselves, making trust unlikely to develop (Malhotra \& Murnighan, 2002). Molm et al. (2000) and Cheshire et al. (2010) also suggest that trust is less likely to develop in negotiated exchange with explicit binding agreements rather than in reciprocal exchange without such agreements. Therefore, formal contractual rules can limit signaling goodwill and generating social reciprocity, thus making social bonds difficult to develop. Conversely, informal and normative constraints featured by binding expectations, morals, and social obligations usually take time and effort to be agreed and internalized by people (Scott, 2013).

In platform organizations including those that are part of the sharing economy, it is common for organizations to integrate and balance both types of institutional constraints to regulate and structure member behaviors (Sibai et al., 2015). For instance, the home-swapping platform HomeExchange.com not only uses legal obligations and penalties to control members' misconduct and cancellations but has also developed 'Community Guidelines' and the 'Home Exchange Etiquette. ${ }^{20}$ Nonetheless, in terms of relative importance, some sharing economy organizations more strongly promote informal constraints such as community guidelines and help sites, expectations for appropriate conducts and etiquette, as well as popularizing community notions, experiences and icons in the platform blog (Acquier et al., 2017; Albinsson \& Perera, 2012), whereas others rely more on contractual clauses and strict sanctions, e.g. Terms and Conditions, Privacy Policies, or written agreements. Regarding the former, communal norms and shared experiences aim to strengthen members' interactions and generate a sense of community (Garrett, Spreitzer, \& Bacevice, 2017). Sharing economy organizations without a legal statement of any contractual relationships, rights, obligations, and penalties also exist (Hausemer et al., May 2017). For instance, WWOOF, which facilitates the exchanges of farming labor and free accommodation, and Mama Bake, which allows women to share home-made food, depend on communal norms and shared experiences. For the latter, cases like Ola and Uber in ride-hailing, Park On My Drive in space-sharing, and ThredUp in goods-sharing, barely rely on explicitly formulated reciprocal norms. They have instead established clear definitions and comprehensive provisions on the contractual relation and sanctions (Hausemer et al., May 2017).

A significant number of sharing economy organizations combine formal and informal rules to establish appropriate conduct of participants but differ in terms of giving more weight to communal norms and shared experiences or contractual arrangements and sanctions. Consequently, we consider that having a stronger focus on developing communal norms and shared experiences is more compatible with forming social bonds, while a reliance on extensive contractual clauses and stringent penalties may impede this process, thus revealing a stronger tendency to drive economic transactions instead.

\subsubsection{Providing intensive assurance instruments}

The degree to which organizations provide intensive assurance instruments - e.g. verification, ratings and reviews, and monitoring

\footnotetext{
${ }^{20}$ Home Exchange Etiquette. (2018). HomeExchange.com Retrieved 16 March 2018, from https://homeexchange.zendesk.com/hc/en-us/articles/115004127725-HomeExchange-Etiquette
}

devices - is the sixth governance practice that we identify. Uncertainty resulting from incomplete information and opportunism tends to limit the effectiveness of ex-ante contracts (Akerlof, 1970; Williamson, 1979). In addition to the formal contracts and sanctions, alternative control mechanisms can be adopted to mitigate this situation (Williamson, 1985). As illustrated in Section 4.2.1, social bonds developed through positive reciprocal interaction could fulfill this role by exchanging tacit information to reduce information asymmetry (Krackhardt, 1992; Powell, 1990) and by forming 'a base of trust that can reduce resistance and provide comfort in the face of uncertainty' (Krackhardt, 1992, p. 218). In contrast, assurance instruments reduce the exchange uncertainty and contribute to trust by managing information visibility (ter Huurne et al., 2017). Some platforms provide tailored guarantee and insurance schemes to sharing participants, increasing people's confidence and feeling of security by sharing the risk with them. These assurances have become a prominent alternative control mechanism for digital platforms to facilitate efficient exchanges when no prior experience is available (Kramer, 1999; Williamson, 1979; Zucker, 1986).

Trade-offs exist, however, between cooperation supported by assurance instruments and cooperation based on reciprocal interaction (Cheshire, 2011; Cook et al., 2005). Cheshire (2011) proposes that even though assurance instruments and reciprocal interaction can both lead to cooperation, only through long-term interactions can bonded relations and interpersonal trust be generated. In the absence of reciprocal interaction, one-off cooperation that depends on assurance instruments is unlikely to turn into long-term relationships of trust and even bears the risk of endangering or substituting trust. Since assurance instruments have already reduced the uncertainty in exchanges, the need for interpersonal trust, i.e. bonded relations, is undermined (Cheshire, 2011; Cheshire et al., 2010). Although assurance instruments can be efficient to connect people, the connection is largely founded on the rational calculation between reduced risk and potential gain in an environment where opportunism and distrust are presumed (Williamson, 1979). Therefore, a strong reliance on assurance instruments tends to substitute for rather than strengthen the trust relationship (Nissenbaum, 2004).

In the sharing economy, different organizations either seek a balance between the implementation of assurance instruments and the patient nurturing of positive reciprocal interaction or rely on one of them. As risk generated by incomplete information and opportunism is exceptionally high when private assets are exchanged among strangers, sharing economy organizations have adopted various assurance instruments - such as rating and review systems of Airbnb and Couchsurfing, monitoring and GPS tracking devices of Uber and Getaround, and Host Guarantee of Airbnb and Love Home Swap - to reduce information asymmetry and exchange uncertainty (Mauri et al., 2018). With the rating and review system, users can obtain contextbased, tacit information about their counterparts before the sharing process and evaluate if they are trustworthy without conducting direct and repeated interactions. The 5-star rating system of Airbnb is more quantified, standardized, and resembles hotel standards. ${ }^{21}$ In contrast, Couchsurfing 's reference system is designed in a more qualitative and personalized style. It is composed of three types of unstructured reviews: Host References, Surfer References, and Personal References (from friends on the platform or people met on other occasions). ${ }^{22}$ So, the review system is not only a tool for delivering fine-grained and tacit information about the shared resources but could be designed in a less intensive and impersonal way of giving and receiving reciprocal feedback of personal experiences and social signals, which reflects the social

\footnotetext{
${ }^{21}$ Information is based on the rating and review system of Airbnb on 16 March 2018.

${ }^{22}$ Information is based on the rating and review system of Couchsurfing on 16 March 2018.
} 
orientation of the platform. Couchsurfing tries to reduce the quantitative, impersonal and information-provision features of rating, enhancing the feature of social reciprocity, as well as seeking a balance between genuine human interaction and exchange efficiency. Even so, the study of Parigi and State (2014, November) on Couchsurfing shows that while the online reputation system increases the amount of information circulating on the platform, reduces exchange uncertainty and lets users more easily connect, it also leads to a lower binding force of these connections.

In contrast, for the cases which strongly focus on building stronger ties between participants (e.g. Soup Swap, MamaBake), a review system is rarely applied. A large amount of pre-existing reputational information could even exert adverse effects on the highly pro-social and intimate interaction process. Instead of adopting intensive assurance instruments, these organizations depend on the dynamics of reciprocal interaction, offline activities, and fixed groups and communities to develop social norms and govern the sharing process. Although some sharing economy organizations claim to develop trust between people through reliable assurance systems (Newman \& Antin, March 2016; Ufford, February 2015), they are facilitating immediate cooperation and reinforcing exchange security rather than building social relations in a strict sense. Therefore, governing the sharing process by depending on intensive assurance instruments and reducing the importance of reciprocal interactions aligns better with economic transaction facilitation, while refraining from using intensive assurance instruments and relying on reciprocal interaction seems more compatible with social bonding development.

\section{The interplay between governance practices in the governance mix: complementarities and contradictions}

Unpacking the governance practices that promote the identity and incentives, facilitate the interaction forms, and establish the rules and norms of sharing activities reveals the key differences between sharing platforms. The different practices provide the 'ingredients' for a governance mix; while the 'chemical reactions' - the interplay between practices - caused by adding certain 'ingredients' make certain mixes more or less stable. A governance mix that incorporates a highly complementary set of practices is more likely to be implemented and sustained. Yet, a governance mix with many contradictory practices is much less likely to be adopted due to the high cost and risk of maintaining it. Such a governance mix leads to considerable tensions and creates an unstable sharing platform (Laurell \& Sandström, 2017; Murillo et al., 2017). In this section, we analyze how sharing economy organizations combine these 'ingredients' of governance practices to direct, coordinate and control sharing activities by specifying the potential 'chemical reactions' occurring in the governance mix.

As Table 2 shows, when organizations govern their sharing activities by consistently adopting practices that encourage developing social or economic interpersonal relationships, they resemble an ideal type fully geared either towards developing social bonds or economic transactions. On the one end, there is the ideal type of loose and decentralized governance (Bardhi \& Eckhardt, 2012; Constantiou et al., 2017). Organizations govern sharing activities by establishing the core mission, providing the basic platform infrastructure for connections between users, setting up the general norm of interaction, while giving the users the autonomy to manage the details of their exchanges. Platforms that facilitate the sharing of physical assets are more likely to lean towards loose and decentralized governance practices. As the physical asset can already be made observable on the platform, the risk of not delivering the service at the required standard is not so high. On the other end, there is the ideal type of tight and centralized governance (Constantiou et al., 2017). Organizations assume economic rationality of individuals and govern the sharing process through binding contracts, extensive assurance tools, and sanction systems. They not only need to develop a complete technical infrastructure to efficiently match supply and demand but also monitor, negotiate, and discipline the users. Platforms that facilitate the sharing of human assets (i.e., skills) are more likely to rely on tight and centralized governance practices. The quality of the human asset and the skills offered can be rather opaque and difficult to make observable on the platform, so there is a much higher risk of a below-par service delivery.

While the ideal types have internal coherence between their constituent governance practices and bear the least risk of causing tensions and an unstable governance mix, the sharing economy literature shows that organizations tend to blend practices instead to create different kinds of value (Acquier et al., 2017; Murillo et al., 2017). Platforms that facilitate the sharing of human assets are not necessarily just using practices for tight control. For example, Rover.com - a platform that connects pet owners and pet sitters/walkers - combines a good chance of repeated and face-to-face interaction with a fairly high reliance on assurance instruments. It incorporates practices that simultaneously encourage social bonding and economic transactions. There is a potentially rich complexity when organizations orchestrate the practices in line with their dual purpose of pursuing social and economic objectives (Constantiou et al., 2017). An interplay between practices emerges that could be complementary or contradictory because they represent different values, goals, and logics (Besharov \& Smith, 2014; Mair et al., 2015). The mix of governance practices will not be random as some practices have a more natural fit than others. Yet, there can still be a complementary fit between practices even when they encourage different types of interpersonal relationships. And even if a mix of practices creates tensions, some contradictions will be much stronger than others or get intensified in certain contexts (Acquier et al., 2017). In the following, we discuss a selection of interactions between governance practices that create complementarities or contradictions and present some illustrations from the sharing economy literature.

For the motivational dimension, signaling a socially-focused identity can be complementary to facilitating economic transactions because signaling a socially responsible image can bring in more resources and attract consumers (Waddock \& Graves, 1997). Likewise, presenting a commercially focused identity that promises users financial independence gives an organization a better chance to attract investments and improve platform infrastructure, which supports the social and community activities between users. However, a mix of social and commercial objectives could also set rather high requirements on funding different operations and coordinating immediate and long-term interests (et al., 2017) and obscure what is signaled to stakeholders (Galaskiewicz \& Barringer, 2012; Mair et al., 2015), thus leading to contradictions that could hinder the development of economic transactions or social bonds. A case in point is Couchsurfing's change in legal status in 2011 from a non-profit to a 'B Corporation'. The change sent users the signal of a new, more balanced organizational identity, yet it raised controversy about whether the platform could maintain investments in the high level of social interaction and norms in the community (Baker, August 2011; Lapowsky, n.d.).

It is common for sharing economy organizations to offer both social and economic benefits to attract participants with heterogeneous traits and value orientations. However, the demonstration of significant economic benefits, which attracts participants with strong commercial incentives and filters out those pursuing social and emotional value (Kyprianou, 2018), could limit the possibility of having reciprocal interaction and a sense of community among members (Acquier et al., 2017). Users' resistance to HomeExchange.com's shift from delivering non-monetary and egalitarian social benefits to more calculative and economic benefits illustrates this contradiction. By valuing members' homes with a specific number of 'points', the platform's new offering of non-reciprocal but more flexible home swaps caused many users who 
prefer the direct reciprocity and community basis of the traditional home exchange to leave (Zerly, December 2018).

For the interactional dimension, providing greater opportunities for repeated interpersonal interaction can increase the amount of highquality information in the sharing process which generates trust and expands market opportunities, thus contributing to transaction efficiency and revenue making (Granovetter, 1985; Powell, 1990). Fiverr.com and Quirky exemplify platforms that have explored this complementary benefit. Frequent interactions between members, either online or offline, form the major route for freelancers to find gigs ( $\mathrm{Fi}$ verr.com $)^{23}$, and for inventors to get ideas of improving their products (Quirky) ${ }^{24}$. However, in some contexts such as ride-hailing, purposely creating the conditions for such interaction to take place can require considerable time and resources, which makes it unattractive for sharing platforms that focus on optimizing exchange efficiency and scalability.

Also, while face-to-face interaction can complement transactions by improving personal experience, as in the case of social dining, a focus on face-to-face interaction is inflexible or even unnecessary when distant resources are involved, or the efficiency and scale of searching-andmatching becomes a major demand. Examples include ride-hailing platforms or Roomer, a platform where travelers search and book imminent non-cancelable hotel rooms of people who cannot make their trips. In turn, if designed properly, mediated communication technology can increase the chance of online repeated interaction between distant sharing participants and add to the social connection. Skillsharing communities like Quirky thrive almost entirely based on the online environment. A reliance on mediated communication could also limit intricate non-verbal information. It hinders the forming of social attraction and involvement and the generation of social bonds between participants (Bente et al., 2008). A tension Airbnb faces is that its impact on building social connections is compromised in a context where commercial operators use the site for multiple listings. This development sees Airbnb "becoming more like a rental marketplace rather than a spare-room sharing platform" and involves negligible face-to-face interaction between property owners and renters (Ke, 2017).

For the institutional dimension, when well-coordinated, applying formal and informal rules in different parts of the sharing process can generate complementary effects (North, 1992). Many sharing platforms combine the use of contractual terms and sanctions with community norms and experiences. Examples include BlaBlaCar and Wunder in ride-sharing, HomeExchange.com and ShareDesk in space-sharing, and Fiverr.com and SkillShare in skill-sharing. However, a strong reliance on contractual rules and sanctions could contradict the signaling of goodwill or crowd out the incentive of reciprocal interaction for users (Macaulay, 1963). Moreover, cultivating communal norms and shared experiences tends to take time and effort to be agreed and internalized by people. It is therefore treated more as a peripheral investment by organizations such as Ola, Uber, and Roomer that target exchange efficiency and scalability (Scott, 2013).

As for control mechanisms, sharing platforms widely implement assurance instruments to facilitate the initial interaction between sharing participants. For instance, BlaBlaCar's reports show how its adoption of verification, rating, and pre-payment systems manages to build 'trust' and 'bring people closer' (BlaBlaCar, 2018; Mazzella \& Sundararajan, 2016). Paradoxically, there is a risk that a strong reliance on assurance instruments could reduce participants' demand for reciprocal interaction and exchange of reliable, qualitative information in the sharing process and thus limit the generation of social bonds (Cheshire, 2011). Research on Couchsurfing supports the salience of

\footnotetext{
${ }^{23}$ Fiverr Forum. (2020). Fiverr.com. Retrieved 15 January 2020, from https:// forum.fiverr.com/?utm_source $=$ fiverr\&utm_medium $=$ website

${ }^{24}$ How does Quirky work. (2020). Quirky.com. Retrieved 17 January 2020, from https://quirky.com/faqs/
}

this risk (Parigi \& State, 2014, November).

\section{Conclusion}

This paper conceptualizes the governance of sharing activities by looking into the distinct governance practices that sharing economy organizations can resort to, to facilitate two salient but potentially competing interpersonal relationships: social bonding and economic transactions. By unpacking the governance practices that provide incentives, shape interaction forms, and establish rules and norms for sharing relationships, we develop a framework that helps to map out and explain the variation we observe between sharing platforms in terms of how they govern their activities and users' behavior. With our framework we seek to make several contributions to the sharing economy literature.

Firstly, our framework unearths the nature of and the interplay between the governance practices that sharing economy organizations use to facilitate social bonds and economic transactions, respectively. It lays the conceptual foundation to systematically capture how sharing economy organizations combine governance practices into a governance mix. So far, scholars have conceptually captured prototypes of sharing behaviors, identifying their characteristics and mutations, and empirically categorized contemporary sharing practices but they mainly relied on a simple dichotomy of pure sharing and pure exchange (Belk, 2010; Habibi et al., 2016). Our framework goes beyond this dichotomy by showing which governance practices form the basis for building the social and/or economic relationships that sharing economy organizations rely on to encourage user participation for the aim of value creation. Hence, we add to studies that have made headway into identifying governance practices specific to the sharing economy (Mair \& Reischauer, 2017; Perren \& Kozinets, 2018; Reischauer \& Mair, 2018). Reischauer and Mair (2018), for example, identified governance practices of sharing platforms, but they focused mainly on online communities. While they found that offline practices also play a role in the governance of sharing activities, our framework shows in more detail how online and offline practices interact and encourage different types of interpersonal relationships. Our framework provides a more systematic representation of the governance practices that sharing platforms use across different sectors and contexts. It can thus form the starting point for empirical studies in this area. With many controversies still existing on whether sharing economy organizations deliver on the promise of a more community-oriented way of doing business (Acquier et al., 2017; Benkler, 2017; Schor et al., 2016), uncovering how they direct, coordinate and control their users' activities and behavior will increase understanding of the alignment between purpose and practice.

Secondly, our framework offers an approach to explain which practices are more likely to be combined in a governance mix because they are complementary, and which practices seem incompatible instead. We suggest that sharing economy organizations do not use governance practices at random in a governance mix. While organizational objectives and missions are usually considered as the primary factor influencing governance choices, the multiplicity of social and economic objectives calls for an explanation beyond the direct "goal - choice outcome" rationale as well as more awareness of the coordination work between mixed objectives and the exploration of choices. By analyzing the potential interplay between governance practices, we show how complementarities and contradictions can emerge between them. These complementarities and contradictions can either expand or restrict organizations' governance choices, allowing them to create a unique governance mix that aligns well with their complex missions (Constantiou et al., 2017; Mair \& Reischauer, 2017). Our analysis concerning this interplay can also form a stepping-stone for empirical research that seeks to explain the specific mix of governance practices found in sharing platforms. It raises the significance of investigating more complex forces that could have structured these organizations' 
governance choices. Further empirical studies should provide insight into the stability of specific governance mixes and investigate to what extent the purpose and the governance of sharing platforms are aligned.

Finally, our conceptual framework was developed to uncover and explain the complexity of governance in the sharing economy. The main arguments are based on insights from management, marketing, economics and sociology as well as the empirical sharing economy literature. Since we did not use primary evidence, our six practices might not cover all variation that can be observed among sharing platforms. The contradictions and complementarities between the practices that we developed in Section 5 are only propositions at this stage. To validate our framework, empirical research is needed to study how sharing platforms combine various practices in their governance mix. We expect that innovative methods such as fuzzy-set QCA could be employed to empirically capture the different mixes that emerge from the interaction between the governance practices. Despite these challenges, there is much potential to further explore how organizations combine governance practices, how the interplay between them complicates the stability of their platforms, and how contextual factors mediate the governance process. Capturing these complexities and dynamics will be challenging but hopefully provide insight into the further development of the sharing economy over the coming years. Our framework could also help in shedding light on the diversity in governance practices of related organizational forms in the digital era, where individual activities and interpersonal connections enabled by information and communication technology play increasingly important roles, such as platform organizations, online collaborations, and value co-creation.

\section{CRediT authorship contribution statement}

Yaomin Zhang: Conceptualization, Writing - original draft, Writing - review \& editing. Jonatan Pinkse: Conceptualization, Writing - original draft, Writing - review \& editing, Supervision. Andrew McMeekin: Conceptualization, Writing - review \& editing.

\section{Declarations of Competing Interest}

None.

\section{Supplementary materials}

Supplementary material associated with this article can be found, in the online version, at doi:10.1016/j.techfore.2020.120133.

\section{References}

Acquier, A., Daudigeos, T., Pinkse, J., 2017. Promises and paradoxes of the sharing economy: an organizing framework. Technol. Forecast. Soc. Change. https://doi.org/ 10.1016/j.techfore.2017.07.006.

Akerlof, G.A., 1970. The market for "lemons": Quality uncertainty and the market mechanism. Q. J. Econ. 84 (3), 488-500.

Albert, S., Whetten, D.A., 2004. Organizational identity. In: Hatch, M.J., Schultz, M. (Eds.), Organizational Identity: A Reader. Oxford University Press, New York, pp. 89-118.

Albinsson, P.A., Perera, B.Y., 2012. Alternative marketplaces in the 21st century: building community through sharing events. J. Consum. Behav. 11 (4), 303-315. https://doi. org/10.1002/cb.1389.

Altman, E.J., Tushman, M.L., 2017. Platforms, open/user innovation, and ecosystems: a strategic leadership perspective. Entrepreneurship, Innovation, and Platforms. Emerald Publishing Limited, pp. 177-207.

Aptekar, S., 2016. Gifts Among Strangers: The Social Organization of Freecycle Giving. Soc. Probl. 63 (2), 266-283. https://doi.org/10.1093/socpro/spw005.

Baker, V. (August 2011). Not-for-profit Couchsurfing becomes a company (with a conscience). Retrieved fromhttps://www.theguardian.com/travel/2011/aug/26/ couchsurfing-investment-budget-travel.
Bardhi, F., Eckhardt, G.M., 2012. Access-based consumption: the case of car sharing. J. Consum. Res. 39 (4), 881-898. https://doi.org/10.1086/666376.

Barnes, S.J., Mattsson, J., 2017. Understanding collaborative consumption: test of a theoretical model. Technol. Forecast. Soc. Change 118, 281-292.

Belk, R., 2007. Why not share rather than own? Ann. Am. Acad. Political Soc. Sci. 611 (1), 126-140. https://doi.org/10.1177/0002716206298483.

Belk, R., 2010. Sharing. J. Consum. Res. 36 (5), 715-734. https://doi.org/10.1086/ 612649.

Belk, R., 2014. Sharing Versus Pseudo-Sharing in Web 2.0. Anthropologist 18 (1), 7-23 Retrieved from < Go to ISI > ://WOS:000341558100002.

Benkler, Y., 2004. Sharing nicely: On shareable goods and the emergence of sharing as a modality of economic production. Yale Law J. 114 (2), 273-358. https://doi.org/10. $2307 / 4135731$.

Benkler, Y., 2017. Peer production, the commons, and the future of the firm. Strat. Org. 15 (2), 264-274. https://doi.org/10.1177/1476127016652606.

Bente, G., Rüggenberg, S., Krämer, N.C., Eschenburg, F., 2008. Avatar-mediated networking: increasing social presence and interpersonal trust in net-based collaborations. Hum. Commun. Res. 34 (2), 287-318. https://doi.org/10.1111/j.1468-2958. 2008.00322.x.

Besharov, M.L., Smith, W.K., 2014. Multiple institutional logics in organizations: explaining their varied nature and implications. Acad. Manag. Rev. 39 (3), 364-381. https://doi.org/10.5465/amr.2011.0431.

BlaBlaCar, 2018. Bringing People Closer. Retrieved from.

Bogaert, S., Boone, C., Declerck, C., 2008. Social value orientation and cooperation in social dilemmas: a review and conceptual model. Br. J. Soc. Psychol. 47 (Pt 3), 453-480. https://doi.org/10.1348/014466607X244970.

Botsman, R. (2013). The sharing economy lacks a shared definition. Fast Company.

Bridoux, F., Coeurderoy, R., Durand, R., 2011. Heterogeneous motives and the collective creation of value. Acad. Manag. Rev. 36 (4), 711-730. https://doi.org/10.5465/amr. 2009.0440 .

Bucher, E., Fieseler, C., Lutz, C., 2016. What's mine is yours (for a nominal fee) Exploring the spectrum of utilitarian to altruistic motives for Internet-mediated sharing. Comput. Hum. Behav. 62, 316-326. https://doi.org/10.1016/j.chb.2016.04. 002.

Cheshire, C., 2011. Online trust, trustworthiness, or assurance. Daedalus 140 (4), 49-58.

Cheshire, C., Gerbasi, A., Cook, K.S., 2010. Trust and transitions in modes of exchange. Soc. Psychol. Q. 73 (2), 176-195.

Constantiou, I., Marton, A., Tuunainen, V.K., 2017. Four models of sharing economy platforms. MIS Q. Execut. 16 (4).

Cook, K.S., Yamagishi, T., Cheshire, C., Cooper, R., Matsuda, M., Mashima, R., 2005. Trust building via risk taking: a cross-societal experiment. Soc. Psychol. Q. 68 (2), $121-142$.

De Cremer, D., Van Lange, P.A.M., 2001. Why prosocials exhibit greater cooperation than proselfs: The roles of social responsibility and reciprocity. Eur. J. Personal. 15 (S1), S5-S18. https://doi.org/10.1002/per.418.

Doty, D.H., Glick, W.H., 1994. Typologies as a unique form of theory building: toward improved understanding and modeling. Acad. Manag. Rev. 19 (2), 230-251.

Eckhardt, G.M., Bardhi, F., 2015. The sharing economy isn't about sharing at all. Harv. Bus. Rev. 28 (1)

Eckhardt, G.M., Bardhi, F., 2016. The relationship between access practices and economic systems. J. Assoc. Consum. Res. 1 (2), 210-225. https://doi.org/10.1086/684684.

Ert, E., Fleischer, A., Magen, N., 2016. Trust and reputation in the sharing economy: the role of personal photos in Airbnb. Tourism Manag. 55, 62-73. https://doi.org/10. 1016/j.tourman.2016.01.013.

Fagerstrøm, A., Pawar, S., Sigurdsson, V., Foxall, G.R., Yani-de-Soriano, M., 2017. That personal profile image might jeopardize your rental opportunity! On the relative impact of the seller's facial expressions upon buying behavior on Airbnb ${ }^{\mathrm{TM}}$. Comput. Hum. Behav. 72, 123-131. https://doi.org/10.1016/j.chb.2017.02.029.

Fehr, E., Gintis, H., 2007. Human motivation and social cooperation: experimental and analytical foundations. Annu. Rev. Sociol. 33 (1), 43-64. https://doi.org/10.1146/ annurev.soc.33.040406.131812.

Frenken, K., Meelen, T., Arets, M., \& Van de Glind, P. (May 2015). Smarter regulation for the sharing economy. Retrieved fromhttps://www.theguardian.com/science/ political-science/2015/may/20/smarter-regulation-for-the-sharing-economy.

Galaskiewicz, J., Barringer, S.N., 2012. Social Enterprises and Social Categories. pp. 47-70. https://doi.org/10.1057/9781137035301_3.

Garrett, L.E., Spreitzer, G.M., Bacevice, P.A., 2017. Co-constructing a sense of community at work: the emergence of community in coworking spaces. Org. Stud. 38 (6), 821-842. https://doi.org/10.1177/0170840616685354.

Gerwe, O., Silva, R., 2020. Clarifying the sharing economy: conceptualization, typology, antecedents, and effects. Acad. Manag. Perspect. 34 (1), 65-96. https://doi.org/10. 5465/amp.2017.0010.

Giddens, A., 1997. The Constitution of Society. Polity Press, Cambridge.

Gioia, D.A., Schultz, M., Corley, K.G., 2000. Organizational Identity, Image, and Adaptive Instability. Acad. Manag. Rev. 25 (1), 63-81. Retrieved from. http://www.jstor.org/ stable/259263.

Goffman, E., 1990. The Presentation of Self in Everyday Life. Penguin books, London.

Goffman, E., 2005. Interaction Ritual: Essays in Face-to-Face Behavior. AldineTransaction.

Granovetter, M., 1973. The strength of weak ties. Am. J. Sociol. 78 (6), 1360-1380.

Granovetter, M., 1985. Economic Action and Social Structure. Am. J. Sociol. 91 (3), 
481-510.

Habibi, M.R., Kim, A., Laroche, M., 2016. From sharing to exchange: an extended framework of dual modes of collaborative nonownership consumption. J. Assoc. Consum. Res. 1 (2), 277-294. https://doi.org/10.1086/684685.

Hamari, J., Sjoklint, M., Ukkonen, A., 2016. The sharing economy: Why people participate in collaborative consumption. J. Assoc. Inf. Sci. Technol. 67 (9), 2047-2059. https://doi.org/10.1002/asi.23552.

Hausemer, P., Rzepecka, J., Dragulin, M., Psaila, E., Fiorentini, S., Gysen, S., May 2017. Exploratory Study of Consumer Issues in Peer-to-Peer Platform Market. Retrieved from.

Hirschi, T., 1969. A control theory of delinquency. In: Williams IIIFrank P., McShare, M.D. (Eds.), Criminology Theory: Selected Classic Readings. Anderson Publishing Co, Cincinnati.

John, N.A., 2013. The social logics of sharing. Commun. Rev. 16 (3), 113-131.

Ke, Q., 2017. Sharing means renting?: An entire-marketplace analysis of Airbnb. In: Proceedings of the 2017 ACM on Web Science Conference - WebSci '17.

Krackhardt, D., 1992. The strength of strong ties: the importance of philos in organizations. In: Nohria, N., Eccles, R. (Eds.), Networks and Organizations: Structure, Form, and Action. Harvard Business School Press, Boston, MA, pp. 216-239.

Kramer, R.M., 1999. Trust and distrust in organizations: emerging perspectives, eduring questions. Annu. Rev. Psychol 50, 569-598.

Kraut, R.E., Resnick, P., 2012. Building Successful online Communities: Evidence-Based Social Design. MIT Press, Cambridge, MA.

Kyprianou, C., 2018. Creating value from the outside in or inside out: how nascent intermediaries build peer-to-peer marketplaces. Acad. Manag. Discov. https://doi.org/ 10.5465/amd.2017.0081.

Lamberton, C.P., Rose, R.L., 2012. What is ours better than mine? A framework for understanding and altering participation in commercial sharing system. J. Market. 76 (4), 109-125.

Hughes, B. (January 2016). Proven strategies for building trust in the new sharing economy. Retrieved from https://smallbiztrends.com/2016/01/new-sharingeconomy.html.

Laurell, C., Sandström, C., 2017. The sharing economy in social media: analyzing tensions between market and non-market logics. Technol. Forecast. Soc. Change 125, 58-65. https://doi.org/10.1016/j.techfore.2017.05.038.

Licoppe, C., 2004. 'Connected' presence: the emergence of a new repertoire for managing social relationships in a changing communication technoscape. Environ. Plann. D: Soc. Space 22 (1), 135-156.

Lumineau, F., 2014. How contracts influence trust and distrust. J. Manag. 43 (5), 1553-1577. https://doi.org/10.1177/0149206314556656.

Lutz, C., Newlands, G., 2018. Consumer segmentation within the sharing economy: the case of Airbnb. J. Bus. Res. 88, 187-196.

Macaulay, S., 1963. Non-contractual relations in business - a preliminary-study. Am. Sociol. Rev. 28 (1), 55-67. https://doi.org/10.2307/2090458.

Mair, J., Mayer, J., Lutz, E., 2015. Navigating institutional plurality: organizational governance in hybrid organizations. Org. Stud. 36 (6), 713-739.

Mair, J., Reischauer, G., 2017. Capturing the dynamics of the sharing economy: institutional research on the plural forms and practices of sharing economy organizations. Technol. Forecast. Soc. Change 125, 11-20. https://doi.org/10.1016/j.techfore. 2017.05.023.

Malhotra, D., Murnighan, J.K., 2002. The effects of contracts on interpersonal trust. Adm. Sci. Q. 47 (3), 534-559.

Mauri, A.G., Minazzi, R., Nieto-García, M., Viglia, G., 2018. Humanize your business. The role of personal reputation in the sharing economy. Int. J. Hosp. Manag. 73, 36-43. https://doi.org/10.1016/j.ijhm.2018.01.017.

Mazzella, F., Sundararajan, A., 2016. Entering the Trust Age. Retrieved from.

McArthur, E., 2015. Many-to-many exchange without money: why people share their recources. Consump. Mark. Culture 18 (3), 239-256.

Molm, L.D., Takahashi, N., Peterson, G., 2000. Risk and trust in social exchange: an experimental test of a classical proposition. Am. J. Sociol. 105 (5), 1396-1427.

Muñoz, P., Cohen, B., 2017. Mapping out the sharing economy: a configurational approach to sharing business modeling. Technol. Forecast. Soc. Change 125, 21-37. https://doi.org/10.1016/j.techfore.2017.03.035.

Murillo, D., Buckland, H., Val, E., 2017. When the sharing economy becomes neoliberalism on steroids: Unravelling the controversies. Technol. Forecast. Soc. Change 125, 66-76. https://doi.org/10.1016/j.techfore.2017.05.024.

Lapowsky, I. (May 2012). Couchsurfing Dilemma: Going for Profit. Retrieved from https://www.inc.com/magazine/201206/issie-lapowsky/couchsurfing-new-profitmodel.html.

Newman, R., \& Antin, J. (March 2016). Building for trust: Insights from our efforts to distill the fuel for the sharing economy. Retrieved fromhttps://medium.com/airbnbengineering/building-for-trust-503e9872bbbb.

Nissenbaum, H., 2004. Will Security Enhance Trust online, or supplant it? In: Kramer, R.M., Cook, K.S. (Eds.), Trust and Distrust in Organizations: Dilemmas and Approaches. Russell Sage Foundation, New York.

Nooteboom, B., 2002. Trust: Forms, Foundations, Functions, Failures And Figures. Edward Elgar Publishing.

North, D.C., 1992. Institutions, Institutional Change and Economic Performance. Cambridge University Press, Cambridge.
Parigi, P., State, B., 2014, November, November. Disenchanting the world: The impact of technology on relationships. In: Proceedings of the International Conference on Social Informatics.

Perren, R., Kozinets, R.V., 2018. Lateral exchange markets: how social platforms operate in a networked economy. J. Market. 82 (1), 20-36. https://doi.org/10.1509/jm.14. 0250 .

Polanyi, K., 1957. The Great Transformation: The Political and Economic Origins of Our Time. Beacon Press, Boston.

Pollman, E., Barry, J.M., 2016. Regulatory entrepreneurship. South. Calif. Law Rev. 90, 383-448.

Porter, C.E., Donthu, N., 2008. Cultivating trust and harvesting value in virtual communities. Manag. Sci. 54 (1), 113-128. https://doi.org/10.1287/mnsc.1070.0765.

Powell, W.W., 1990. Neither market nor hierarchy: network forms of organizations. Res. Org. Behav. 12, 295-336.

Quélin, B.V., Kivleniece, I., Lazzarini, S., 2017. Public-private collaboration, hybridity and social value: towards new theoretical perspectives. J. Manag. Stud. 54 (6), 763-792. https://doi.org/10.1111/joms.12274.

Reischauer, G., Mair, J., 2018. How organizations strategically govern online communities: lessons from the sharing economy. Acad. Manag. Discov. 4 (3), 220-247. https://doi.org/10.5465/amd.2016.0164.

Roos, D., Hahn, R., 2017. Understanding collaborative consumption: an extension of the theory of planned behavior with value-based personal norms. J. Bus. Ethics. https:// doi.org/10.1007/s10551-017-3675-3.

Schor, J.B., October 2014. Debating the Sharing Economy. Great Transit. Initiat Retrieved from. http://www.greattransition.org/publication/debating-the-sharing-economy.

Schor, J.B., Fitzmaurice, C., Carfagna, L.B., Attwood-Charles, W., Poteat, E.D., 2016. Paradoxes of openness and distinction in the sharing economy. Poetics 54, 66-81. https://doi.org/10.1016/j.poetic.2015.11.001.

Schor, J.B., Fitzmaurice, C.J., 2015. Collaborating and connecting: The emergence of the sharing economy. In: Reisch, L., Thogersen, J. (Eds.), Handbook of Research on Sustainable Consumption. Edward Elgar, Cheltenham, UK, pp. 410.

Scott, W.R., 2013. Institutions and Organizations: Ideas, Interests, and Identities, Fourth Edition. Sage Publications.

Sheth, J.N., Newman, B.I., Gross, B.L., 1991. Why we buy what we buy: a theory of consumption values. J. Bus. Res. 22 (2), 159-170.

Sibai, O., de Valck, K., Farrell, A.M., Rudd, J.M., 2015. Social control in online communities of consumption: a framework for community management. Psychol. Market. 32 (3), 250-264. https://doi.org/10.1002/mar.20778.

Sitkin, S.B., Roth, N.L., 1993. Explaining the limited effectiveness of legalistic "remedies" for trust/distrust. Organ. Sci. 4 (3), 367-392.

Sundararajan, A., 2016. The Sharing Economy: The End of Employment and the Rise of Crowd-Based Capitalism. MIT Press, Cambridge, MA.

Tenbrunsel, A.E., Messick, D.M., 1999. Sanctioning systems, decision frames, and cooperation. Adm. Sci. Q. 44 (4), 684-707.

ter Huurne, M., Ronteltap, A., Corten, R., Buskens, V., 2017. Antecedents of trust in the sharing economy: a systematic review. J. Consum. Behav. 16 (6), 485-498. https:// doi.org/10.1002/cb.1667.

Tönnies, F., 1887/2001. In: Hollis, M., Harris, Trans.J. (Eds.), Cambridge University Press, Cambridge Original work published in 1887.

Ufford, S. (February 2015). The future of the sharing economy depends on trust. Retrieved fromhttps://www.forbes.com/sites/theyec/2015/02/10/the-future-of-thesharing-economy-depends-on-trust/\#38f634dd4717.

Waddock, S.A., Graves, S.B., 1997. The corporate social performance-financial performance link. Strat. Manag. J. 18 (4), 303-319.

Weintraub, E. R. (2007). Neoclassical economics: the concise encyclopedia of economics Retrieved fromhttps://www.econlib.org/library/Enc1/NeoclassicalEconomics.html.

Whetten, D.A., 2016. Albert and Whetten revisited: strengthening the concept of organizational identity. J. Manag. Inquiry 15 (3), 219-234. https://doi.org/10.1177/ 1056492606291200.

Whittaker, S., 2003. Theories and methods in mediated communication. In: Graesser, A., Gernsbacher, M., Goldman, S. (Eds.), The Handbook of Discourse Processes. Lawrence Erlbaum, Mahwah, NJ, pp. 243-286.

Wiertz, C., Ruyter, K., 2007. Why customers contribute to firm-hosted commercial online communities. Organ. Stud. 28 (03), 347-376.

Williamson, O.E., 1979. Transaction-cost economics: The governance of contractual relations. J. Law Econ. 22 (2), 233-261.

Williamson, O.E., 1985. The Economic Institutions of Capitalism. Firms, Markets, Relational Contracting. The Free Press, New York.

Williamson, O.E., 2005. The economics of governance. Am. Econ. Rev. 95 (2), 1-18.

Wruk, D., Oberg, A., Klutt, J., Maurer, I., 2019. The presentation of self as good and right: how value propositions and business model features are linked in the sharing economy. J. Bus. Ethics. https://doi.org/10.1007/s10551-019-04209-5.

Zelizer, V.A., 1988. Beyond the polemics on the market: Establishing a theoretical and empirical agenda. Sociol. Forum 3 (4), 614-634.

Zelizer, V.A., 2012. How i became a relational economic sociologist and what does that mean. Politics Soc. 40 (2), 145-174. https://doi.org/10.1177/0032329212441591.

Zerly, D. (December 2018). Home exchange networks merge: A rough integration between GuesttoGuest and HomeExchange.com.

Zucker, L.G., 1986. Production of trust: Institutional sources of economic structure, 
1840-1920. Res. Organ. Behav. 8, 53-111.

Yaomin Zhang holds a Master degree of Sociology. Before joining the Alliance Manchester Business School, she studied in the Department of Sociology of Peking University. During this period, she worked on organisational sociology and labour studies, graduating with a master thesis about digital platforms, ICT and labour governance. She is currently working on her doctoral dissertation which deal with the development of social relationships in the sharing economy.

Jonatan Pinkse is a Professor of strategy, innovation, and entrepreneurship and Executive Director of the Manchester Institute of Innovation Research at the Alliance Manchester Business School, The University of Manchester. His research interests focus on corporate sustainability, social and sustainable entrepreneurship, business model innovation and the sharing economy. His work has appeared in various different journals such as the Academy of Management Review, Research Policy, Journal of Management Studies, Journal of International Business Studies, Organization Studies, Journal of Business Venturing and Entrepreneurship Theory and Practice. He is associate editor at Organization \& Environment and Business \& Society.

Andrew McMeekin is Professor of Innovation at the Alliance Manchester Business School and the Sustainable Consumption Institute (SCI), The University of Manchester. He was Research Director of the SCI between 2012 and 2018 and Deputy Director of the ESRC, Scottish Government and Defra funded Sustainable Practices Research Group between 2010 and 2013. His research interests focus of sociotechnical system transition, sustainability, urban transitions and the emergence of digital (sharing) platforms. His work has appeared in various journals, including Research Policy, Technological Forecasting \& Social Change, Environment and Planning A, Urban Studies, Economy \& Society and Global Environmental Change. 